\title{
Big Data: The Next-Gen Google
}

\author{
Farah Deeba Hasan \\ Student, M.Tech.(IT) \\ Amity School of Engineering \\ and Technology \\ Amity University, Noida, U.P. \\ India
}

\author{
Anshul Kumar Sharma \\ Student, M.Tech.(IT) \\ Amity School of Engineering \\ and Technology \\ Amity University, Noida, U.P. \\ India
}

\author{
Abhilasha Singh \\ Assistant Professor \\ Amity School of Engineering \\ and Technology \\ Amity University, Noida, U.P. \\ India
}

\begin{abstract}
This paper describes the concept of BIG Data and its research areas have been explored. This paper presents what all changes big data can bring to day-to-day lives. There are some life changing projects which can completely change the way people thing and look at data. Some new trends like Internet of Things , Big Data Visualisation, big data and phone technology all these concepts has been discussed in this paper.
\end{abstract}

\section{General Terms}

Big Data, Big Data Visualisation

\section{Keywords}

Big Data, New trends, The human face of big data, phones and androids apps.

\section{INTRODUCTION}

It is rightly said that invention is the mother of necessity. Big Data - A new word in the information world. It is said in contrast to technology that the things that's going to impact in the coming next ten years is already present from past ten years, therefore Big Data is not a new word but with increase in volume now recognition has been given to it.

When it comes to Big Data then it is rightly said that we have to stop thinking small. We mostly think about simpler questions like "how to store more amounts of data?" or "how to analyze it in new way?" This thinking is basically because main focus is on technology and new forms of data in abstract way. To make most of it we need to start thinking big like -

- What's the best technology to handle all of data not the isolated one?

- How to combine it with the analytics system to yield greatest impact in present contrast?

- How better products and services can be created?

In short, we can say that we need to weave together Big data and Data science together to create a better service and support. Some recent areas where this technology is giving an edge to it are [8]:

- Products with memories- Radio-frequency identification a good option because they already used to track. So they now used as having memories that stores entire history from cradle to grave.

- Electronic paper- can be seen in devices like Amazon's Kindle where device is used as e-book with no LED backlight and data is present over web.

- Open content management- people connect and share their ideas on Wikipedia, Facebook or twitter etc. Key attribution for all this is the software that works who owns what for anyone.

- The semantic web- everything is there on web and it would have meaning then it will do a lot of things for people in others words information will come to people then people going to it.

Big data idea gives is a laborious work, its initial benefits are small and also a lot more patients is needed to fully utilize all its functionalities.

\section{BIG DATA - THE SMALL DATA}

Some new themes from day to day usage of Big Data can be:

1.1.Diverse perspectives: it is different for big and small enterprises. Big enterprises see it as opportunity to collect, crunch, cleanse and analyse huge volume of data form multiple system. While small enterprises invest in right marketing channel based on specific needs.

2.2 Consumers always rule the day: companies tries to prelude best practice to consumer so as to invest in right marketing and service channel.

2.3 Big data is no silver bullet: well planned, well tested along with human insight is still needed for the proper working of this technology.

2.4 The right data is the right stuff for it: it is necessary that the right source data is checked and utilized within it for more effective processing.

Keeping these points in mind and with the researches done so far it is understood able that big data leads to logically data which is "small" and these small data is separated from the complex and unstructured datasets. Now analysing this dataset is easier, and more accessible. Therefore it is rightly said by Dr Duncan R Shaw [9]:

"Big data is also 'small data'-many services are not based on massive scale processing, but real time sandbox analytics certainly depends on very fast processing . The huge size of the data assets originally caught our imagination but the speed and specificity of personalisation are what a user vales the most ".

\section{NEW TRENDS}

Technology is the most stable thing, it changes with day-today life. So how can big data be behind. Some of the new trends of these fast growing technologies are as follows:

3.1 Internet of Things: it is indicated that by 2020 up to 100 billion uniquely identified objects will be connected to the internet but human understanding and processing power will not keep a pace with it. So big data here will play a big role in social media. 
3.2 Big Data Visualisation: It's a data-driven era, data is continuously being acquired and timely decisions are crucial for business, clinical treatment, national security etc. Big data analytics and discovery present new research opportunities to visualization community.

3.3 The Human Face of Big Data: It is a crowd sourced media project focusing on humanity's new ability to collect, analyze, triangulate and visualize vast amount of data in real time.

\section{INTERNET OF THINGS}

Now a day's machine to machine wireless communication is being there but still it is like Small Island of systems. A next huge opportunity is the -Internet of Things, which will try to connect all existing system with wireless sensor network (WSN) and other technologies. Data will travel making its own decision, while the big data cloud automatically transfer users preference with him. Ashton wrote in a 1999 article for the RFID Journal that [11]:

"If we had computers that knew everything there was to know about things - using data they gathered without any help from us -- we would be able to track and count everything, and greatly reduce waste, loss and cost. We would know when things needed replacing, repairing or recalling, and whether they were fresh or past their best. We need to empower computers with their own means of gathering information, so they can see, hear and smell the world for themselves, in all its random glory. RFID and sensor technology enable computers to observe, identify and understand the worldwithout the limitations of human-entered data."

With the advent of IPv6 many new devices have been registered and now mobile data has improved a lot. Benefits of Internet of Things can are below:

1. It will connect both inanimate and living things.

2. It can be used as a sensor for data collection.

3. It can change the type of communication over IP network.

Now how IoT uses big data then it uses sensor to collect information from people and system. Earlier it was not easy to collect all information. Then it control and automate the devices remotely like shutting it down health status. It will save cost as it provide actual performance data not just estimate. These benefits are just a few. Some basic knowledge to get most of this technology and see how big data is useful in this is as follow:

- What type of information is needed from sensor: The information provided by sensor should be clearly understood. It must be considered that it will help improve which sector of business. For example [11], sensor data that highlights anomalies in equipment vibration can be used to predict and avoid equipment failure.

- An IOT network and security foundation should be build: A secure and standard IOT network should be build over the IP network so that the data collected is reliable and business performance is improved.

- Data must be collected: Each sensor contribute a small amount of data. Sometimes companies collect all data of the data which is not beneficial. A effective strategy must be build so as to which data is to be included in information extraction. Here big data plays a major role in collecting storing and analyzing.

\section{BIG DATA VISUALIZATION}

In Today's world, marketers ask a lot of questions like, what are my customers' favourite purchases. How can social media be used to better engage their customers? etc and successful marketers knows where to find the answers i.e. in their data[13]. We have entered into a age where data driven marketing is recognition and integration of information to deliver the best possible result. Earlier marketer was dependent on transactional data- for example purchase history, life events, etc. But not data driven marketing is collecting and collecting from online as well as offline data and rapidly analyzing it. Marketers cited the following challenges to drive their organization's marketing initiatives with customer data [13]:

$>$ Our operation, financial, sales, customer and demographic data is collected, stored and analyzes in isolation, thus preventing us from garnering a 360-degree customer view.

$>$ The data we've collected is in different regions, different formats, exists in varing levels of quality.

$>$ Our marketing process is delayed because data insight takes too long for us to identity.

$>$ It's difficult for us to connect the dots between insight, planning, marketing programming, spend and the go-to-market process.

Using big data produces big results. Today customers are in control of marketers. Marketer knows the living habits of every region and likewise plans his business. So its clear that it time for big data visualization.

\section{PHONES AND BIG DATA: THE HUMAN FACE OF BIG DATA-A Case Study}

Cell phone have change the way people think live their life. Phone has gone through many phases of changes. Today Iphone's, androids windows are popular in market. Iphone and cloud are already in market and very successful but now its time for big data and Iphone to mark its presence. They will change the way customer interact with companies, having their own charge to decide what data to share and at what price. Some points what Iphone big data will do areas follows:

$>$ It captures customer's history of product and services purchases etc.

$>$ It constantly scours the web, news outlets and social media sites for events and activates of customer interest.

$>$ It puts consumer in control of their data so that they decide when, where and how to share it with merchants and service provider.

\section{THE HUMAN FACE OF BIG DATA- A case study}

The human face of big data is a globally crowd sourced media project focusing on humanity's new ability to collect, analyze, triangulate and visualize vast amount of data in real time. This Smartphone survey app, in less than 2 months about 3 million share and compare questions has been answered. By these 
responses an insight conclusions towards men and women attitude have been found out like

- A question asks "What is more important for good health - diet, exercise, environment or genes?" for Americans good health is in their hands by exercising and diet, while Europeans believe health is predetermined and out of their control.

- Other question was "What do you do to help cope with stress most?" and answer was that as people get older work and prayer tend to replace friends or the arts as primary means of stress relief.

This project focus on the internet, how it impact people's lives, how human race is learning to heal itself [15]. It shows that how emerging technologies have more potential on impact on civilization than internet. Every photograph in this book have a inside story. After the success story of this book a app was also launched to animate that story. Each video has an amazing sense of intimacy people in more than 30 countries and they all focus about how data, sometimes big and sometime soon to be big, is touching such an astounding array of human life across the world.

This book tries to explain that big data technology is giving us a whole new thing, a whole new dimension to look through the world.

\section{CONCLUSION}

Big data has opened a wide new space for development and has improved the way of thinking. A example of "palo alto" program called Quake Catcher can be considered. it says that sense vibration of mobile phones and laptops connected over internet over 30-mile area can be use to detect that's its an earthquake. By this way sec before the actual earthquake the train and factories can be stopped, people can be alerted. Same way GPS system can tell the alert message about the traffic so that it can change its route. Implementing same project can cost billion dollar but along with lot of engineering. While we can use the sensor which are already present in mobiles and laptops or in GPS system just a infrastructure to process data in real-time will be needed, which wont cost as much as a implementing a whole structure. Likewise big data can helps a lot if successfully implemented.

\section{REFERENCES}

[1] White paper "Challenges and Opportunities with Big Data"

[2] Big Data A New World of Opportunities Jun Hou, Lei Xu,"A Testing Tool for Composite Web Services based on data flow", Sixth web information systems and applications conference, 2009

[3] http://wikibon.org/blog/big-data-statistics/Boris Beizer, "software testing techniques", International Thomas Computer Press, 1990

[4] http://www.lavastorm.com/blog/post/taming-datavariety-and-volatility-is-key-for-big-dataanalytics/A.Rembiszewski "Data flow coverage of object programs" Msc thesis, Institute of Computer Science, Warsaw university of technology,2009

[5] 2013 big datasurver research brief by SAS

[6] http://en.wikipedia.org/wiki/Big_data

[7] http://www.mongodb.com/use-cases/big-data

[8] "The next Google" a special report by Nature.

[9] "Big-Data-Trends-Briefing" by Digital-Cream-London2013

[10] "Introduction to IoT" by Lopez research in November 2013.

[11] http://en.wikipedia.org/wiki/Internet_of_Thing

[12] http://www.idtechx.com/iot-and-wsneurope/home.asp

[13] White paper "data-driven-marketing" published by Teradata Corporation

[14] http://infocus.emc.com/william_schmarzo/my-bigdataiphone-visions

[15] http://www.huffingtonpost.com/philsimon/the-humanface-of-big-bata.htmt 